\title{
Correction to: Wave propagation characteristics of the electrically GNP-reinforced nanocomposite cylindrical shell
}

\author{
Mostafa Habibi $^{1,2} \cdot$ Masoud Mohammadgholiha ${ }^{3} \cdot$ Hamed Safarpour ${ }^{4} \oplus$
}

Published online: 15 May 2019

(C) The Brazilian Society of Mechanical Sciences and Engineering 2019

\section{Correction to: Journal of the Brazilian Society of Mechanical Sciences and Engineering (2019) 41:221 https://doi.org/10.1007/s40430-019-1715-x}

The article Wave propagation characteristics of the electrically GNP reinforced nanocomposite cylindrical shell, written by Hamed Safarpour, was originally published electronically on the publisher's internet portal (currently SpringerLink) on 12/04/2019 with open access.

With the author(s)' decision to step back from Open Choice, the copyright of the article changed on [07/05/2019] to (C) The Brazilian Society of Mechanical Sciences and Engineering 2019 and the article is forthwith distributed under the terms of copyright.
Publisher's Note Springer Nature remains neutral with regard to jurisdictional claims in published maps and institutional affiliations.

The original article can be found online at https://doi.org/10.1007/ s40430-019-1715-x.

Hamed Safarpour

hamed_safarpor@yahoo.com

1 Center of Excellence in Design, Robotics and Automation, School of Mechanical Engineering, Sharif University of Technology, Tehran, Iran

2 Department of Mechanical Engineering, Sharif University of Technology, Tehran, Iran

3 Civil Engineering Department, K.N. Toosi University of Technology, Tehran, Iran

4 Department of Mechanics, Faculty of Engineering, Imam Khomeini International University, Qazvin, Iran 